\title{
21st Century Locomotive Technology: Quarterly Technical Status Report 15 DOE/AL68284-TSR15
}

This is the quarterly status report for the 21st Century Locomotive Technology project, DOE Award DE-FC04-2002AL68284. This report covers activities performed July 2006 to Sept 2006.

TASK 1: ADVANCED FUEL INJECTION....................................................................................... 1

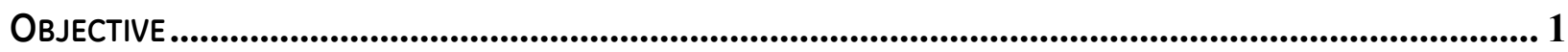

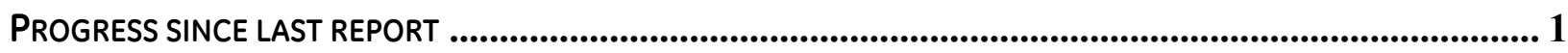

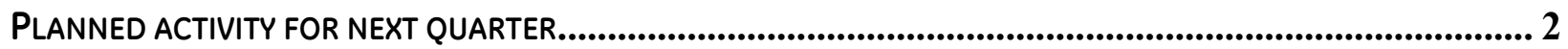

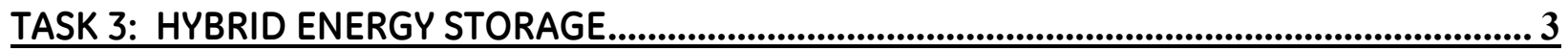

PROGRESS SINCE LAST REPORT ............................................................................................... 3 


\title{
Task 1: Advanced Fuel Injection
}

\author{
Objective
}

Develop and demonstrate an advanced fuel injection system to minimize fuel consumption, while meeting Tier 2 emissions levels.

\section{Progress since last report}

Over the third quarter, we continued common rail fuel system testing on the locomotive single cylinder engine at GE Global Research. The testing facility was well utilized and the uptime productivity reached an all-time high over the last quarter.

There are three main experimental accomplishments in the area of advanced fuel injection:

1. Completed high pressure common rail (HPCR) performance testing over a range of notches (N2 thru N8), acquiring a first order notch-by-notch performance comparison between HPCR and the production fuel system.

2. Completed a multiple injection screening study at notch 8 with the baseline HPCR fuel injector nozzle tip design. A new data collection technique was used to cover the design space more efficiently.

3. Initiated a study to explore the performance effects of different nozzle tip geometries.

Previous HPCR studies included performance testing at two notches, full load and part load. Over the last quarter we collected data over a range of notches to get an indication of how the engine performance compares across the speed load points using the two different fuel systems (i.e. HPCR and Unit Pump System.) This data is important since the locomotive duty cycle performance is a weighted average of all notches.

A majority of the experimental testing has been focused on screening the engine performance at various fuel injection strategies at N8 engine operation. The independent parameters are fuel injection pressure, number and relative timing of fuel injections. The objective of the study is to identify a multiple injection fuel strategy that reduces fuel consumption at Tier 2 NOx levels. Instead of tuning the fuel injection [timing] phasing to get precisely the target NOx, we used a new method to screen fuel injection strategies that did not require this time-consuming tuning process. The screening methodology involved collecting two data points at each injection strategy as shown in Fig. 1. One data point is slightly advanced, yielding higher than target NOx, and the second is slightly retarded, yielding lower than target NOx. By interpolating, we estimate the fuel consumption at the target NOx emission level. The target NOx value was set to the NOx level produced on the single cylinder engine with the production unit pump system at the appropriate fuel injection timing (nominal production engine fuel injection timing.) In this manner, we are able to quickly quantify the fuel consumption impact from each particular injection strategy and rail 
pressure. We tried numerous fuel injection strategies and have discovered multiple injection strategies that give better performance compared with single injection strategies on our single cylinder research engine. These findings will be summarized to the DOE at our next face-to-face meeting.

Finally, we have begun a study to understand the performance effect of fuel injector nozzle geometry. The first parameter that we are studying is the flow area of the nozzle. We are working with Bosch to procure injector nozzles with desirable and robust performance. This is an iterative process.

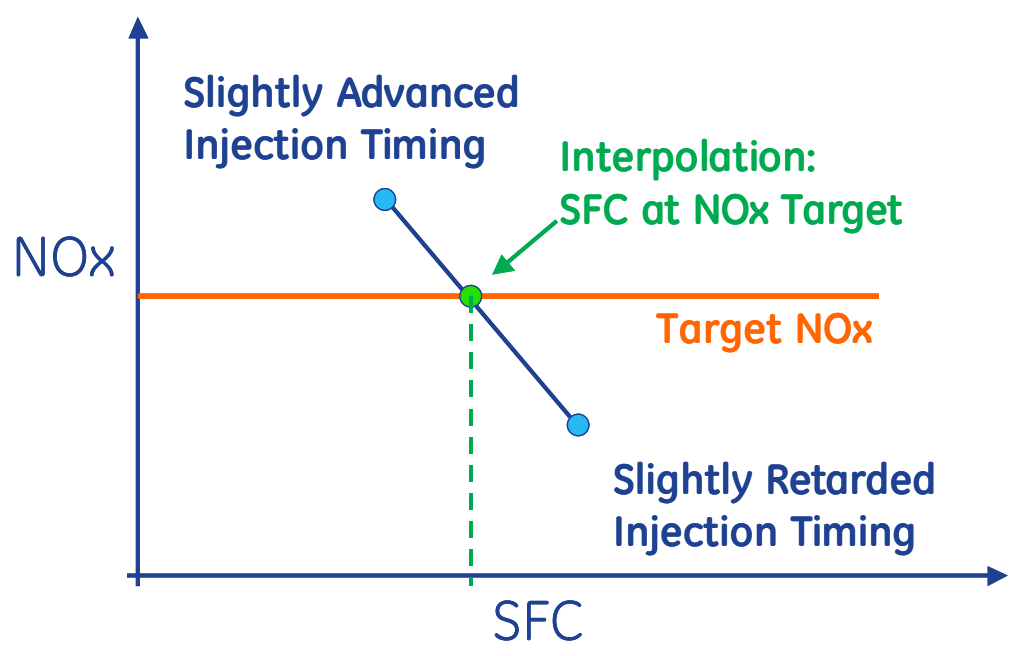

Figure 1 - Approach for screening experiments involved collecting two data points at each fuel injection strategy and estimating SFC performance at target NOx emissions.

Other activities:

Members of the team attended the Diesel Engine - Efficiency and Emissions Research Conference (DEER) in Detroit, MI on August 20-24. This was a report-out and technologysharing event sponsored by the DOE. A majority of the work reported was focused on truck and other on-road engines; however, the technology is not dissimilar from what is needed on locomotive scale engines for upcoming emission regulations. In particular, it was useful to learn about technology trends, product suppliers, and emissions measurement techniques.

\section{Planned activity for next quarter}

Over the next quarter, we will continue to investigate how the HPCR injector nozzle geometry affects the engine performance. As the year closes, there are maintenance and calibrations scheduled in our testing facility. In addition, we are integrating ongoing test cell improvements including real-time particulate matter characterization. 


\section{Task 3: Hybrid Energy Storage}

\section{Progress since last report}

Earlier work in this project identified the need to improve the performance of the hybrid locomotive battery module in high vibration environments. GE and the vendor have coordinated efforts to enhance the battery packaging to better suit the demanding vibration requirements. In this project quarter, the vendor has performed component fabrication tests to assess the manufacturability of the design, and begun manufacture of a "mockup" example battery to validate the performance of the vibration design. The mockup battery will be instrumented and tested on a vibration tester under cold and unenergized conditions in the near future 